\title{
Synergistic Effects of Dual-Electrocatalyst FeOOH/NiOOH Thin Films as Effective Surface Photogenerated Hole Extractors on a Novel Hierarchical Heterojunction Photoanode Structure for Solar-driven Photoelectrochemical Water Splitting
}

\author{
Chong Siang Yaw ${ }^{1}$, Junwang Tang ${ }^{2}$, Ai Kah Soh ${ }^{3}$, Meng Nan Chong ${ }^{*}$ \\ ${ }^{1}$ School of Engineering, Chemical Engineering Discipline, Monash University Malaysia, Jalan Lagoon Selatan, \\ Bandar Sunway, Selangor Darul Ehsan 47500, Malaysia \\ ${ }^{2}$ Department of Chemical Engineering, University College London, Torrington Place, London WC1E 7JE, United \\ Kingdom \\ ${ }^{3}$ School of Engineering, Mechanical Engineering Discipline, Monash University Malaysia, Jalan Lagoon Selatan, \\ Bandar Sunway, Selangor Darul Ehsan 47500, Malaysia
}

"Corresponding author:

Associate Professor Dr. Meng Nan Chong

School of Engineering, Chemical Engineering Discipline, Monash University

Malaysia, Jalan Lagoon Selatan, Bandar Sunway, Selangor DE 47500 Malaysia

Email: Chong.Meng.Nan@monash.edu 


\begin{abstract}
Herein, we report the rational design of a novel hierarchical $\mathrm{V}_{2} \mathrm{O}_{5} / \mathrm{BiVO}_{4}$ heterojunction photoanode structure with rGO interlayer that functionalises as photogenerated electron collector, and dual electrocatalyst thin films of $\mathrm{FeOOH}$ and $\mathrm{NiOOH}$ as photogenerated hole extractors for solar-driven PEC water splitting. Results showed that the novel hierarchical $\mathrm{FTO} / \mathrm{V}_{2} \mathrm{O}_{5} / \mathrm{rGO} / \mathrm{BiVO}_{4} / \mathrm{FeOOH} / \mathrm{NiOOH}$ photoanode exhibited an unprecedented and stable photocurrent density of $3.06 \mathrm{~mA} / \mathrm{cm}^{2}$ at $1.5 \mathrm{~V}$ vs $\mathrm{Ag} / \mathrm{AgCl}$, and an apparent cathodic onset potential shift down to $0.2 \mathrm{~V}$ under AM $1.5 \mathrm{G}$ simulated solar light illumination. The significant enhancement in PEC performance is ascribed to band potentials matching between $\mathrm{V}_{2} \mathrm{O}_{5}$ and $\mathrm{BiVO}_{4}$ in forming a Type II staggered heterojunction alignment, and further coupling with rGO interlayer and dual-electrocatalyst thin films as photogenerated electron collector and photogenerated hole extractors, respectively. Three different configurations of the novel hierarchical $\mathrm{FTO} / \mathrm{V}_{2} \mathrm{O}_{5} / \mathrm{rGO} / \mathrm{BiVO}_{4}$ photoanodes without electrocatalyst, with mono- and dualelectrocatalyst thin films were systematically examined. It was proven though EIS and IMPS measurements that the dual-electrocatalyst configuration photoanode exhibited the shortest transit time $(\tau)$ of $31.8 \mathrm{~ms}$ for the diffusion of photogenerated electrons to the counter electrode, and the lowest charge transfer resistance across the interface of electrode/electrolyte as estimated using the Randles-Ershel model. We believe that the proof-of-principle work described here not only provides an in-depth understanding on the roles of electrocatalyst thin films but also provides a design guide over the incorporation of electrocatalyst materials for further improving the photogenerated charge carrier dynamics in photoanodes used in solardriven PEC water splitting.
\end{abstract}

KEYWORDS: Bismuth vanadate; Heterojunction; Reduced graphene oxide; Electrocatalysts; Photoelectrochemical water splitting 


\section{Introduction}

Since the discovery of the Honda-Fujishima effect, overwhelming attention has been focused on the photoelectrochemical (PEC) water splitting by harnessing solar energy to directly dissociate water molecules into renewable hydrogen $\left(\mathrm{H}_{2}\right)$ fuels and oxygen $\left(\mathrm{O}_{2}\right)$ molecules [1]. At the core of PEC water splitting system for solar-to-hydrogen (STH) energy conversion is the semiconductor-based photoelectrodes used, which absorb solar photons resulting in the formation of photogenerated charge carriers (i.e. electrons and holes) [2-5]. In principle, the PEC water splitting reaction involves oxygen evolution reaction (OER) at the photoanode (Eq. 1) and hydrogen evolution reaction (HER) at the photocathode (Eq. 2).

$$
\begin{aligned}
& \mathrm{H}_{2} \mathrm{O}+2 h^{+} \rightarrow \frac{1}{2} \mathrm{O}_{2}+2 \mathrm{H}^{+} \\
& 2 \mathrm{H}^{+}+2 e^{-} \rightarrow \mathrm{H}_{2}
\end{aligned}
$$

Over the last five decades, various semiconductor materials have been studied in addition to the titanium dioxide $\left(\mathrm{TiO}_{2}\right)$ for application in PEC water splitting for solar $\mathrm{H}_{2}$ fuels production. To date, however, there is no singular semiconductor material that met the ideal requirements for application in practical PEC water splitting such as having high stability under the operating conditions, high STH efficiency, and cost inexpensiveness [6-8]. Among all, bismuth vanadate $\left(\mathrm{BiVO}_{4}\right)$ is regarded as one of the most promising photoanode materials used for PEC water splitting. Ideally, $\mathrm{BiVO}_{4}$ fulfills many of practical requirements for PEC water splitting for solar $\mathrm{H}_{2}$ fuels production, such as having relatively narrow band gap $\sim 2.5 \mathrm{eV}$ that absorbs a substantial portion of visible light spectrum, earth abundance, low cost, environmentally benign and possesses a favourable conduction band (CB) edge position that is very near to the thermodynamic $\mathrm{H}_{2}$ evolution potential $[9,10]$. Whilst in terms of the charge carriers dynamics, the effective mass of photogenerated charge carriers in $\mathrm{BiVO}_{4}$ is much lighter than other photoactive semiconductor materials. This implies that they have a higher probability to reach the surface reaction sites within their exciton lifetime [11].

Thus far, the practical efficiency of PEC water splitting using singular $\mathrm{BiVO}_{4}$ photoanode is still far from its theoretical maximum photocurrent density of $7.5 \mathrm{~mA} / \mathrm{cm}^{2}$ under AM 1.5 G illumination [12]. This is due to the excessive recombination of electron-hole pairs, poor charge transport properties and high surface reaction kinetic barriers when using the singular $\mathrm{BiVO}_{4}$ photoanode in PEC water splitting [13, 14]. Recently, Zachäus and co-workers reported that the generation of photocurrent on $\mathrm{BiVO}_{4}$ photoanode is not limited by its surface 
reaction kinetics but surface recombination of photogenerated charge carriers [15]. Furthermore, $\mathrm{BiVO}_{4}$ photoanode suffers from both chemical and photochemical instability under aqueous condition [16]. In order to overcome these issues, the effective separation and transfer of the photogenerated charge carriers within the photoanode structure is crucial. Proper band potentials alignment and hybridisation of functionalised thin films within the heterojunction photoanode structure to extract both the photogenerated charge carriers out of the bulk $\mathrm{BiVO}_{4}$ are an effective way to mitigate the issues associated with surface recombination and photostability $[17,18]$.

One of the common approaches to extract photogenerated holes from bulk $\mathrm{BiVO}_{4}$ is by introducing either oxygen evolution reaction (OER) or hydrogen evolution reaction (HER) electrocatalyst to reduce the interfacial charge carriers recombination at the semiconductor/OER junction while creating a more favorable Helmholtz layer potential drop at the OER/electrolyte junction [19-21]. Theoretically, the introduction of OER electrocatalyst onto photoanode structure is inherently more complex and may result in a higher efficiency loss than when introducing HER electrocatalyst. This is due to that OER requires four-electrons transfer step with the removal of four protons from water molecules to generate one $\mathrm{O}_{2}$ molecule and thus, leading to a large overpotential requirement to facilitate the reaction efficiently $[19,22]$. To date, the most commonly used OER electrocatalysts on photoanode for PEC water splitting are precious noble metals oxides, such as ruthenium (IV) oxide $\left(\mathrm{RuO}_{2}\right)$ and iridium (IV) oxide ( $\left.\mathrm{IrO}_{2}\right)$ [23]. Nevertheless, the utilisation of OER electrocatalysts loaded onto photoanode for large-scale practical PEC water splitting is constrained by the resource-scarcity of noble metals and their high-cost [24]. Balsara et al. found that the first row transition metalbased OER cocatalysts are very promising candidates due to their high stability, abundance in nature, low-cost and advanced catalytic performance that is comparable to the noble metalbased OER cocatalysts $[25,26]$. With the introduction of OER cocatalysts, it is expected to provide active sites for interfacial reaction with reducing overpotential requirement, enhanced PEC stability through efficient extraction of photogenerated charge carriers from bulk semiconductor and a physical thin film barrier that protects the bulk semiconductor surface from direct contact with electrolyte used [27, 28].

Herein, in this study, we report a rational design of a novel hierarchical vanadium pentoxide $\left(\mathrm{V}_{2} \mathrm{O}_{5}\right) / \mathrm{BiVO}_{4}$ heterojunction photoanode structure with reduced graphene oxide (rGO) interlayer on fluorine-doped tin oxide (FTO) substrate and topping with dual transitionmetal electrocatalyst thin films of ferric $(\mathrm{FeOOH})$ and nickel oxyhydroxide $(\mathrm{NiOOH})$ for 
improving the overall efficiency for solar-driven PEC water splitting. $\mathrm{V}_{2} \mathrm{O}_{5}$ has been intensively investigated as a superior candidate for stimulating the water oxidation reaction with a band gap of 2.3- $2.8 \mathrm{eV}$ for solar capturing and an appropriate band energy level for PEC water splitting [29]. The band potentials matching between $\mathrm{V}_{2} \mathrm{O}_{5}$ and $\mathrm{BiVO}_{4}$ enables the formation of a Type II staggered heterojunction photoanode that allows more photogenerated electrons to reach the counter electrode and more photogenerated holes to reach the surface of $\mathrm{BiVO}_{4}[29,30]$. Whilst further coupling with rGO interlayer promotes efficient interfacial charge transfer and reduce the electron injection barrier between $\mathrm{V}_{2} \mathrm{O}_{5}$ and $\mathrm{BiVO}_{4}$. Additionally, the synergistic effects of introducing dual electrocatalyst thin films of $\mathrm{FeOOH}$ and $\mathrm{NiOOH}$ as efficient photogenerated hole extractors were also examined. In particular, the charge carriers separation and injection properties of the novel hierarchical photoanode were investigated in the presence of hole scavenger, hydrogen peroxide $\left(\mathrm{H}_{2} \mathrm{O}_{2}\right)$ with facile oxidation kinetics. Both electrochemical impedance spectroscopy (EIS) and intensity-modulated photocurrent spectroscopy (IMPS) measurements were performed to gain an insight into the transport of photogenerated charge carriers, recombination processes and kinetics of PEC water splitting reactions at the interfacial of heterojunction photoanode structure. This study will provide a new insight on the rational design of heterojunction photoanode structure with hybridised thin films that act as both photogenerated electron collector and hole extractor, and the synergistic effects that arise through the formation of novel hierarchical heterojunction photoanode structure for PEC water splitting.

\section{Experimental Section}

\subsection{Materials}

Vanadium (IV) oxide sulfate hydrate $\left(\mathrm{VOSO}_{4}, 97 \%\right)$ was obtained from Sigma Aldrich, USA. Nitric acid $\left(\mathrm{HNO}_{3}, 69 \%\right)$ and anhydrous sodium acetate $\left(\mathrm{CH}_{3} \mathrm{COONa}\right)$ were obtained from Friendemann Schmidt Chemical, Germany; absolute ethanol $\left(\mathrm{C}_{2} \mathrm{H}_{6} \mathrm{O}\right)$, hydrogen peroxide $\left(\mathrm{H}_{2} \mathrm{O}_{2}\right)$ (30 wt $\%$ ), sulfuric acid $\left(\mathrm{H}_{2} \mathrm{SO}_{4}\right)$ (96 wt\%), phosphoric acid $\left(\mathrm{H}_{3} \mathrm{PO}_{4}\right)$ (75 wt $\%$ ), potassium permanganate $\left(\mathrm{KMnO}_{4}\right)$, hydrochloric acid $(\mathrm{HCl})(30 \mathrm{wt} \%)$, graphite powder, iron (III) sulphate heptahydrate (FeSO4.7H2O), nickel (III) sulphate hexahydrate (NiSO4.6H2O), sodium hydroxide $(\mathrm{NaOH})$ and sodium sulfate $\left(\mathrm{Na}_{2} \mathrm{SO}_{4}\right)$ were purchased from Merck, Germany. Bismuth nitrate pentahydrate $\left(\mathrm{Bi}\left(\mathrm{NO}_{3}\right)_{3} \cdot 5 \mathrm{H}_{2} \mathrm{O}\right)$ was purchased from $\mathrm{R} \& \mathrm{M}$ Chemicals, United Kingdom. FTO glass was purchased from Kaivo Optoelectronic 
Technology, China. The FTO glass substrate (14 $\Omega /$ sq) was cut and cleaned using acetone, ethanol and deionised water in an ultrasonic bath for $20 \mathrm{~min}$. All the reagents were of analytical grade and used without further purification.

\subsection{Preparation of $\mathrm{V}_{2} \mathrm{O}_{5} / \mathrm{BiVO}_{4}$ heterojunction photoanode with rGO interlayer}

Graphene oxide (GO) was prepared via the Improved Hummers' method due to its facile and cost-effective synthesis procedures. Briefly, a thin film of GO was coated onto the FTO substrate through drop-casting $240 \mu \mathrm{L}$ of the $0.5 \mathrm{mg} / \mathrm{mL}$ GO dispersion. This was followed by the electrodeposition of $\mathrm{V}_{2} \mathrm{O}_{5}$ thin film onto the GO-coated FTO substrate. The electrodeposition of $\mathrm{V}_{2} \mathrm{O}_{5}$ thin film was carried out by applying $1.5 \mathrm{~V}$ vs $\mathrm{Ag} / \mathrm{AgCl}(3 \mathrm{M})$ for 10 min using a precursor aqueous solution containing $0.2 \mathrm{M} \mathrm{VOSO}_{4}$ and $20 \mathrm{~mL}$ ethanol at $\mathrm{pH} 1.8$ adjusted using 95-99 \% $\mathrm{H}_{2} \mathrm{SO}_{4}$. The $\mathrm{FTO} / \mathrm{V}_{2} \mathrm{O}_{5}$ samples were annealed at $400{ }^{\circ} \mathrm{C}$ for $1 \mathrm{hr}$. To prepare the subsequent rGO interlayer on the annealed FTO/ $\mathrm{V}_{2} \mathrm{O}_{5}$ samples, $320 \mu \mathrm{L}$ of 0.5 $\mathrm{mg} / \mathrm{mL}$ GO dispersion was drop-casted on top of $\mathrm{V}_{2} \mathrm{O}_{5}$ thin film followed by electrochemical reduction of $\mathrm{GO}$ at an applied bias range of -1.5 to $0.5 \mathrm{~V}$ vs $\mathrm{Ag} / \mathrm{AgCl}$ for 4 cycles in $0.1 \mathrm{M}$ $\mathrm{Na}_{2} \mathrm{SO}_{4}$ electrolyte. The final $\mathrm{BiVO}_{4}$ thin film was prepared on top of the rGO interlayer following a modified electrodeposition method [31]. Specifically, $10 \mathrm{mM} \mathrm{Bi}\left(\mathrm{NO}_{3}\right)_{3}$ and $35 \mathrm{mM}$ $\mathrm{VOSO}_{4}$ were separately dissolved in $0.5 \mathrm{M} \mathrm{HNO}_{3}$ as the $\mathrm{Bi}$ and $\mathrm{V}$ precursor solutions, respectively. The $\mathrm{pH}$ value of the electrolyte was raised to $\mathrm{pH} 5.1$ using $2 \mathrm{M} \mathrm{CH}_{3} \mathrm{COONa}$, and then adjusted to a final $\mathrm{pH}$ of $\mathrm{pH} 4.7$ using $69 \% \mathrm{HNO}_{3}$. The electrodeposition was carried out potentiostatically at $1.9 \mathrm{~V}$ vs $\mathrm{Ag} / \mathrm{AgCl}$ for $45 \mathrm{~min}$. Finally, the as-deposited films were rinsed and then annealed at $400{ }^{\circ} \mathrm{C}$ for $1 \mathrm{hr}$ in air environment.

\subsection{Electrodeposition of $\mathrm{FeOOH}$ and photo-assisted electrodeposition of $\mathrm{NiOOH}$}

A thin film of $\mathrm{FeOOH}$ was conformally electrodeposited on the $\mathrm{FTO} / \mathrm{V}_{2} \mathrm{O}_{5} / \mathrm{rGO} / \mathrm{BiVO}_{4}$ heterojunction photoanode from a $0.1 \mathrm{M} \mathrm{FeSO}_{4} .7 \mathrm{H}_{2} \mathrm{O}$ aqueous solution by applying an external bias of $0.65 \mathrm{~V} \mathrm{vs} \mathrm{Ag} / \mathrm{AgCl}(3 \mathrm{M} \mathrm{KCl})$. The electrodeposition synthesis process was halted after it has exceeded the total charge threshold of $0.42 \mathrm{mC} / \mathrm{cm}^{2}$. During the electrodeposition synthesis process, $\mathrm{Fe}^{2+}$ ions were oxidised to $\mathrm{Fe}^{3+}$ ions that precipitated out as $\mathrm{FeOOH}$ on top of $\mathrm{BiVO}_{4}$ thin film. As for the photo-assisted electrodeposition synthesis of $\mathrm{NiOOH}$, the $\mathrm{FTO} / \mathrm{V}_{2} \mathrm{O}_{5} / \mathrm{rGO} / \mathrm{BiVO}_{4} / \mathrm{FeOOH}$ heterojunction photoanode was transferred to a three- 
electrode PEC cell containing $0.5 \mathrm{M} \mathrm{NiSO}_{4} .6 \mathrm{H}_{2} \mathrm{O}$ in which the $\mathrm{pH}$ was adjusted to $\mathrm{pH} 7$ by using $1 \mathrm{M} \mathrm{NaOH}$. A $150 \mathrm{~W}$ Xenon light with an output intensity of $100 \mathrm{~mW} / \mathrm{cm}^{2}$ was used as the illumination source for solar-driven PEC water splitting (Abet Technologies Model 10500, United States). During the illumination, $\mathrm{Ni}^{2+}$ ions were oxidised to $\mathrm{Ni}^{3+}$ ions that precipitated out as $\mathrm{NiOOH}$ on top of $\mathrm{FeOOH}$ thin film. To facilitate the photo-assisted electrodeposition synthesis of $\mathrm{NiOOH}$, an external bias of $0.4 \mathrm{~V}$ vs $\mathrm{Ag} / \mathrm{AgCl}$ was applied. The photo-assisted electrodeposition process was stopped after a total charge of $0.6 \mu \mathrm{C} / \mathrm{cm}^{2}$ was attained.

\subsection{Characterisation}

The prepared photoanodes were characterised by using X-ray powder diffraction (XRD) on a Bruker D8 Discover diffractometer (Hitachi SU8010, Japan) equipped with Ni-filtered Cu-Ka radiation at the scan rate of $0.02^{\circ} \mathrm{s}^{-1}$. The measurements were collected using an accelerating voltage and applied current of $40 \mathrm{kV}$ and $40 \mathrm{~mA}$ respectively to obtain its crystalline phase composition. Electron transparent focused ion beam (FIB) lamellae were prepared by using a FEI Nova 200 Nanolab Dual Beam FIB instrument from United States. A final clean was performed using a $5 \mathrm{kV}$ gallium beam, while a $12 \mathrm{pA}$ gallium beam was used to remove the material deposited during FIB preparation as well as to reduce damage from the initial milling process. This was followed by low energy argon cleaning. A thin film of electron beamdeposited platinum followed by a gradient of fine-to-coarse grained ion beam platinum were deposited to minimise the ion beam interaction with the exposed surface throughout the transmission electron microscopy (TEM) sample preparation.

UV-vis diffuse reflectance spectra were recorded on a UV-vis spectrophotometer (Agilent Cary 100, United States) equipped with an integrated sphere. X-ray photoelectron spectroscopy (XPS) measurements were performed using a scanning X-ray microprobe PHI Quantera II (Ulvac-PHI, INC.) with a monochromatic Al-Ka $(\mathrm{h} v=1486.6 \mathrm{eV}) \mathrm{X}$-ray source. Linear sweep voltammetry (LSV), IMPS, cyclic voltammetry and EIS were measured in a three-electrode cell system using an applied potentiostat/galvanostat (Metrohm PGSTAT 204 model, Netherlands), where the $\mathrm{Pt}$ rod and a saturated $\mathrm{Ag} / \mathrm{AgCl}(3 \mathrm{M})$ were used as counter and reference electrode, respectively. Nyquist analyses were acquired with a frequency range of $100 \mathrm{kHz}-0.1 \mathrm{~Hz}$ at $1.2 \mathrm{~V}$ bias voltage with FRA32M frequency analyser (Metrohm-Autolab, The Netherlands). Mott-Schottky analyses were performed at $10 \mathrm{kHz}$ by scanning the potential range from -0.1 to $0.9 \mathrm{~V}$ at $0.05 \mathrm{~V} \mathrm{~s}^{-1}$ sweep rate. IMPS measurements were conducted using 
a potentiostat connected to a high intensity light emitting diode (cool white LED) controlled by LED driver that allowed the superimposition of sinusoidal modulation on a DC illumination level. The light intensity was modulated by $10 \%$ between $10 \mathrm{kHz}$ and $0.1 \mathrm{~Hz}$.

\section{Results and Discussion}

XRD measurements were carried out and shown in Fig. 1 (a) to examine the phase purity of a series of as-prepared photoanodes along with the information on their crystalline structure. The XRD pattern of the $\mathrm{FTO} / \mathrm{V}_{2} \mathrm{O}_{5} / \mathrm{BiVO}_{4}$ heterojunction photoanode structure demonstrated that the $\mathrm{BiVO}_{4}$ existed in its monoclinic scheelite phase (JCPDS Card No. 14-0688) and $\mathrm{V}_{2} \mathrm{O}_{5}$ in its orthorhombic phase (JCPDS Card No. 72-433) [32]. Meanwhile, the XRD peaks at 38, 51.7, $61.8,65.7^{\circ}$ for all the photoanode structures were ascribed to the FTO substrate used [33]. There are no distinct XRD diffraction peaks that can be observed in the novel hierarchical $\mathrm{FTO} / \mathrm{V}_{2} \mathrm{O}_{5} / \mathrm{rGO} / \mathrm{BiVO}_{4}$ photoanode with the dual-electrocatalyst thin films due to the amorphous nature of both the $\mathrm{FeOOH}$ and $\mathrm{NiOOH}$ thin films. However, both the EDX elemental mapping and XPS analysis revealed the existence and distribution of $\mathrm{Fe}$ and $\mathrm{Ni}$ element on the outermost surface of $\mathrm{FTO} / \mathrm{V}_{2} \mathrm{O}_{5} / \mathrm{rGO} / \mathrm{BiVO}_{4}$ photoanode. The cross-sectional low magnification TEM image shown in Fig. 1 (b) reveals the uniform dispersion of both $\mathrm{Fe}$ and $\mathrm{Ni}$ elements over $\mathrm{BiVO}_{4}$ of the $\mathrm{FTO} / \mathrm{V}_{2} \mathrm{O}_{5} / \mathrm{rGO} / \mathrm{BiVO}_{4}$ photoanode. Fig. 1 (c) and (d) show the Fe $2 \mathrm{p}$ and Ni 2p XPS spectra with major peaks of 712.6, 726.3, 856.3 and $874.3 \mathrm{eV}$, respectively, which are a good evidence to validate the presence of $\mathrm{FeOOH}$ and $\mathrm{NiOOH}$ thin films $[34,35]$. 

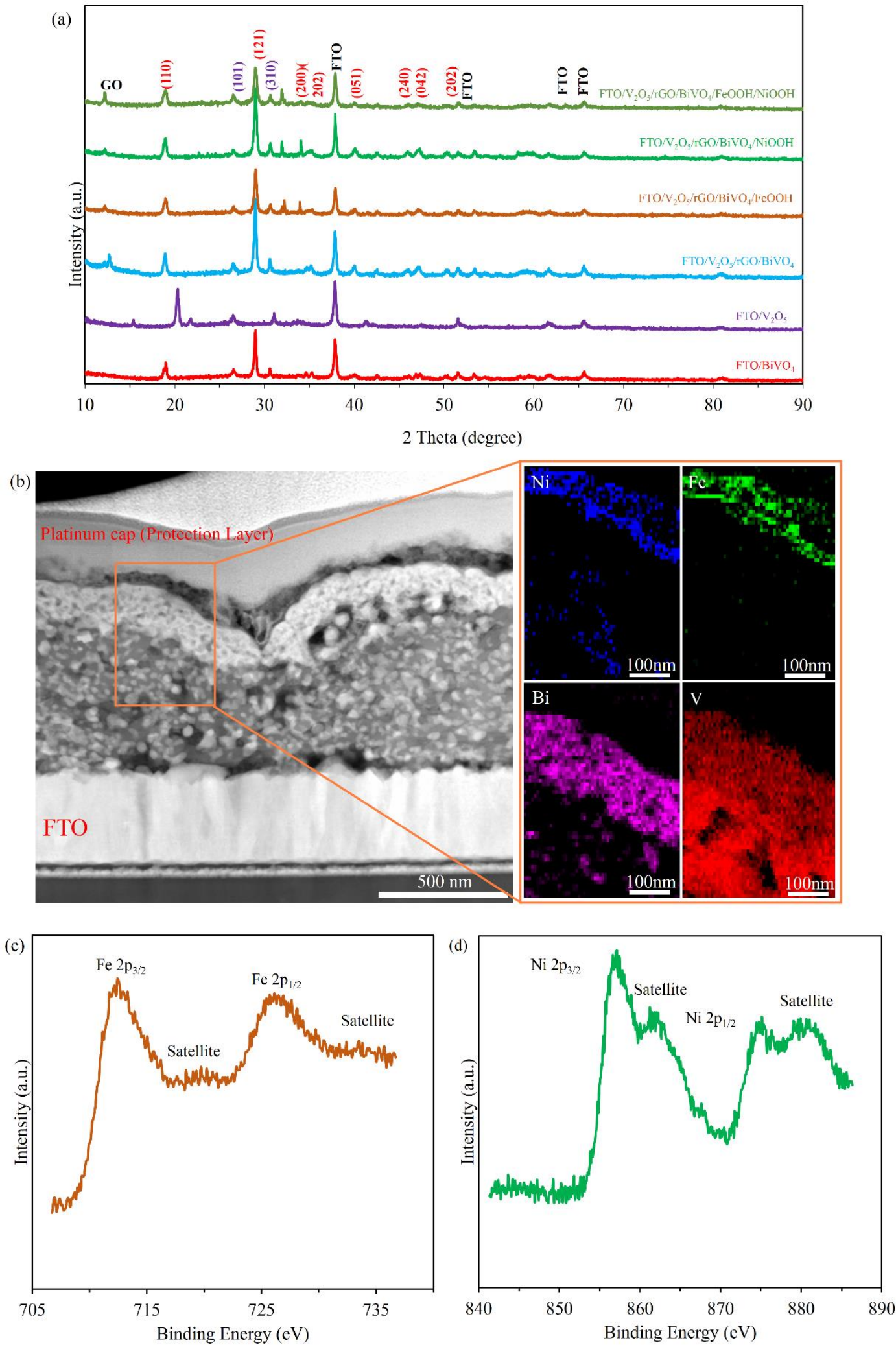

Fig. 1. (a) XRD patterns of the as-prepared photoanode structures. (b) Element mapping and XPS spectra of (c) Fe 2p and (d) Ni 2p for hierarchical $\mathrm{FTO} / \mathrm{V}_{2} \mathrm{O}_{5} / \mathrm{rGO} / \mathrm{BiVO}_{4} / \mathrm{FeOOH} / \mathrm{NiOOH}$ photoanode. 
The optical band gap energies of the monoclinic $\mathrm{BiVO}_{4}$ scheelite phase and orthorhombic $\mathrm{V}_{2} \mathrm{O}_{5}$ phase can be determined from the plot of Kubelka-Munk function $(\alpha h v)^{2}$ versus incident light energy (hv), where $\alpha$ is absorption co-efficient in $\mathrm{cm}^{-1}, \mathrm{~h}$ is the Planck constant $\left(6.626 \times 10^{-34}\right.$ $\mathrm{J} . \mathrm{s})$ and $\mathrm{v}$ is the frequency of light $(\mathrm{Hz})$ [36]. By extrapolating a linear line of the curve that meets at the $\mathrm{x}$-axis intercept, the optical band gap energies of $\mathrm{BiVO}_{4}$ and $\mathrm{V}_{2} \mathrm{O}_{5}$ are determined to be $2.55 \mathrm{eV}$ and $2.49 \mathrm{eV}$ as shown in Fig. 2(a) and (b), respectively. Fig. 2 (c) illustrates the optical property of $\mathrm{FTO}_{\mathrm{BiVO}}, \quad \mathrm{FTO} / \mathrm{V}_{2} \mathrm{O}_{5} / \mathrm{rGO} / \mathrm{BiVO}_{4} \quad$ and $\mathrm{FTO} / \mathrm{V}_{2} \mathrm{O}_{5} / \mathrm{rGO} / \mathrm{BiVO}_{4} / \mathrm{FeOOH} / \mathrm{NiOOH}$ photoanodes as measured by using $\mathrm{UV}-$ vis diffuse reflectance spectrophotometer. With the construction of heterojunction photoanode structure between $\mathrm{BiVO}_{4}$ and $\mathrm{V}_{2} \mathrm{O}_{5}$ as well as the introduction of $\mathrm{rGO}$ interlayer, the light absorption ability in the visible region was increased from $495 \mathrm{~nm}$ to $585 \mathrm{~nm}$. When the heterojunction photoanode structure of $\mathrm{FTO} / \mathrm{BiVO}_{4} / \mathrm{V}_{2} \mathrm{O}_{5}$ was constructed, two shoulders were observed in its light absorption profile that corresponded well to the absorbance of $\mathrm{BiVO}_{4}$ and $\mathrm{V}_{2} \mathrm{O}_{5}$. It was, however that no absorption edge was observed indicating the rGO interlayer in the current system does not have an energy gap [37]. In comparison to the $\mathrm{FTOV}_{2} \mathrm{O}_{5} / \mathrm{BiVO}_{4}$ heterojunction structure with $\mathrm{rGO}$ interlayer, the novel hierarchical FTO/ $\mathrm{V}_{2} \mathrm{O}_{5} / \mathrm{rGO} / \mathrm{BiVO}_{4} / \mathrm{FeOOH} / \mathrm{NiOOH}$ photoanode was demonstrated to have a broadened light absorption range and enhanced light absorption intensity which are beneficial for the wider utilisation of the solar spectrum.
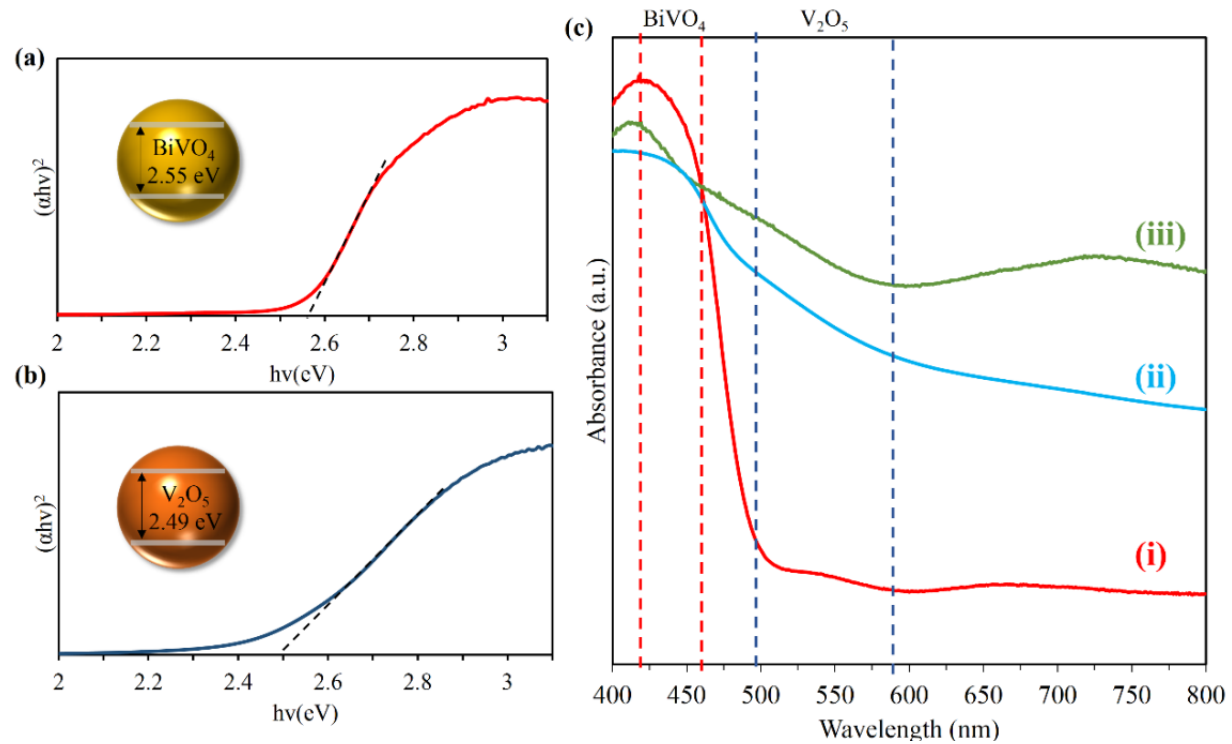

Fig. 2. Tauc plot of pristine (a) $\mathrm{BiVO}_{4}$ and (b) $\mathrm{V}_{2} \mathrm{O}_{5}$, (c) $\mathrm{UV}$-vis diffuse reflectance spectra for (i) $\mathrm{FTO} / \mathrm{BiVO}_{4}$, (ii) $\mathrm{FTO} / \mathrm{V}_{2} \mathrm{O}_{5} / \mathrm{rGO} / \mathrm{BiVO}_{4}$ and (iii) $\mathrm{FTO} / \mathrm{V}_{2} \mathrm{O}_{5} / \mathrm{rGO} / \mathrm{BiVO}_{4} / \mathrm{FeOOH} / \mathrm{NiOOH}$. 
In this study, all the PEC analysis was performed using the standard three-electrode configuration in $0.5 \mathrm{M} \mathrm{Na}_{2} \mathrm{SO}_{4}$ electrolyte solution. Fig. 3 (a) shows the photocurrent densitypotential curves of $\quad \mathrm{FTO} / \mathrm{BiVO}_{4}, \quad \mathrm{FTO} / \mathrm{V}_{2} \mathrm{O}_{5} / \mathrm{BiVO}_{4}, \quad \mathrm{FTO} / \mathrm{V}_{2} \mathrm{O}_{5} / \mathrm{rGO} / \mathrm{BiVO}_{4}$, $\mathrm{FTO} / \mathrm{V}_{2} \mathrm{O}_{5} / \mathrm{rGO} / \mathrm{BiVO}_{4} / \mathrm{FeOOH}$, $\mathrm{FTO} / \mathrm{V}_{2} \mathrm{O}_{5} / \mathrm{rGO} / \mathrm{BiVO}_{4} / \mathrm{NiOOH}$ and $\mathrm{FTO} / \mathrm{V}_{2} \mathrm{O}_{5} / \mathrm{rGO} / \mathrm{BiVO}_{4} / \mathrm{FeOOH} / \mathrm{NiOOH}$ photoanode structures under $\mathrm{AM} 1.5 \mathrm{G}$ simulated solar light illumination. All the LSV curves were examined for two prominent features, namely; (1) photocurrent density measured at $1.5 \mathrm{~V}$ vs $\mathrm{Ag} / \mathrm{AgCl}$, and (2) photocurrent onset potential. As shown in Fig. 3 (a), the pristine $\mathrm{BiVO}_{4}$ exhibits a very low photocurrent density of only $0.25 \mathrm{~mA} / \mathrm{cm}^{2}$ at $1.5 \mathrm{~V}$ vs $\mathrm{Ag} / \mathrm{AgCl}$ under front illumination. With the construction of $\mathrm{FTO} / \mathrm{V}_{2} \mathrm{O}_{5} / \mathrm{rGO} / \mathrm{BiVO}_{4}$ heterojunction structure, a significantly improved photocurrent density of 9-fold higher than that of pristine $\mathrm{BiVO}_{4}$ was observed and reaching a photocurrent density of $2.1 \mathrm{~mA} / \mathrm{cm}^{2}$ at $1.5 \mathrm{~V}$ vs $\mathrm{Ag} / \mathrm{AgCl}$. When a thin film of $\mathrm{FeOOH}$ and $\mathrm{NiOOH}$ electrocatalyst was decorated on top of the $\mathrm{FTO} / \mathrm{V}_{2} \mathrm{O}_{5} / \mathrm{rGO} / \mathrm{BiVO}_{4}$ photoanode structure, the measured photocurrent density was seen to increase to 2.54 and $2.59 \mathrm{~mA} / \mathrm{cm}^{2}$ at $1.5 \mathrm{~V}$ vs $\mathrm{Ag} / \mathrm{AgCl}$, respectively.

When compared to the mono-electrocatalyst thin film configuration of $\mathrm{FTO} / \mathrm{V}_{2} \mathrm{O}_{5} / \mathrm{rGO} / \mathrm{BiVO}_{4} / \mathrm{FeOOH}$ and $\mathrm{FTO} / \mathrm{V}_{2} \mathrm{O}_{5} / \mathrm{rGO} / \mathrm{BiVO}_{4} / \mathrm{NiOOH}$, the dual-electrocatalyst configuration of $\mathrm{FTO} / \mathrm{V}_{2} \mathrm{O}_{5} / \mathrm{rGO} / \mathrm{BiVO}_{4} / \mathrm{FeOOH} / \mathrm{NiOOH}$ showed a more remarkable enhancement in terms of its photocurrent density. Results have distinctly showed that the dualelectrocatalyst $\mathrm{FTO} / \mathrm{V}_{2} \mathrm{O}_{5} / \mathrm{rGO} / \mathrm{BiVO}_{4} / \mathrm{FeOOH} / \mathrm{NiOOH}$ photoanode achieved a remarkable photocurrent density of $3.06 \mathrm{~mA} / \mathrm{cm}^{2}$ at $1.5 \mathrm{~V}$ vs $\mathrm{Ag} / \mathrm{AgCl}$, which was 12 -fold higher than the pristine $\mathrm{BiVO}_{4}$. The significant enhancement in photocurrent density of the novel hierarchical $\mathrm{FTO} / \mathrm{V}_{2} \mathrm{O}_{5} / \mathrm{rGO} / \mathrm{BiVO}_{4} / \mathrm{FeOOH} / \mathrm{NiOOH}$ photoanode is attributed to the synergistic effect of the dual-electrocatalyst configuration, in which the $\mathrm{BiVO}_{4} / \mathrm{FeOOH}$ interface minimises electron recombination at the $\mathrm{BiVO}_{4} / \mathrm{FeOOH}$ junction. Whilst the $\mathrm{NiOOH} /$ electrolyte interface makes the surface charge more favourable, and concurrently improving the overall PEC performance.

Another imperative feature of the LSV as shown in Fig. 3(a) is the photocurrent onset potential. In this instance, the photocurrent onset potential is defined as the potential at the intersection point of the tangent at a maximum slope of photocurrent and the dark current curves. From Fig. 3(a), the onset potential of $\mathrm{FTO} / \mathrm{V}_{2} \mathrm{O}_{5} / \mathrm{rGO} / \mathrm{BiVO}_{4}$ photoanode shows a slight cathodic shift from $0.7 \mathrm{~V}$ to $0.6 \mathrm{~V}$ when compared to the $\mathrm{FTO} / \mathrm{V}_{2} \mathrm{O}_{5} / \mathrm{BiVO}_{4}$ photoanode. This observation is clearly indicating that the $\mathrm{FTO} / \mathrm{V}_{2} \mathrm{O}_{5} / \mathrm{BiVO}_{4}$ photoanode exhibited a lower 
charge injection efficiency than the $\mathrm{FTO} / \mathrm{V}_{2} \mathrm{O}_{5} / \mathrm{rGO} / \mathrm{BiVO}_{4}$ photoanode. When compared to the $\mathrm{FTO} / \mathrm{V}_{2} \mathrm{O}_{5} / \mathrm{rGO} / \mathrm{BiVO}_{4}$ photoanode, it was observed that the photocurrent onset potential of $\mathrm{FTO} / \mathrm{V}_{2} \mathrm{O}_{5} / \mathrm{rGO} / \mathrm{BiVO}_{4} / \mathrm{FeOOH}$ photoanode was significantly reduced from $0.6 \mathrm{~V}$ to $0.3 \mathrm{~V}$ with a cathodic shift of $0.2 \mathrm{~V}$. To a greater extent, the photocurrent onset potential of the $\mathrm{FTO} / \mathrm{V}_{2} \mathrm{O}_{5} / \mathrm{rGO} / \mathrm{BiVO}_{4} / \mathrm{FeOOH}$ photoanode was further cathodically shifted down to $0.1 \mathrm{~V}$ when a $\mathrm{NiOOH}$ thin film was decorated as the outermost layer through the photo-assisted electrodeposition synthesis. The significant cathodic shift of the photocurrent onset potential is greatly due to the reduced surface electron-hole recombination and accelerated OER activity.

In order to further validate and correlate the measured photocurrent density of the $\mathrm{FTO} / \mathrm{V}_{2} \mathrm{O}_{5} / \mathrm{BiVO}_{4}, \quad \mathrm{FTO} / \mathrm{V}_{2} \mathrm{O}_{5} / \mathrm{rGO} / \mathrm{BiVO}_{4}$ and $\mathrm{FTO} / \mathrm{V}_{2} \mathrm{O}_{5} / \mathrm{rGO} / \mathrm{BiVO}_{4} / \mathrm{FeOOH} / \mathrm{NiOOH}$ photoanodes are indeed originated from the water splitting activity, $\mathrm{H}_{2}$ gas evolution measurement was carried out under AM $1.5 \mathrm{G}$ simulated solar light illumination with an applied potential of $1.5 \mathrm{~V}$. In this instance, the absence of the $\mathrm{H}_{2}$ gas evolution from pristine $\mathrm{BiVO}_{4}$ is due to the very low and disproportionate generation of photocurrent density generation of $0.22 \mathrm{~mA} / \mathrm{cm}^{2}$ at $1.5 \mathrm{~V}$ vs $\mathrm{Ag} / \mathrm{AgCl}$. In order to rule out that the enhanced $\mathrm{H}_{2}$ gas evolution rate was resulted from the dual-electrocatalyst configuration, control studies were conducted in the presence of $\mathrm{V}_{2} \mathrm{O}_{5}$ and $\mathrm{rGO}$ interlayer under the similar working conditions. From Fig. 3 (c), the $\mathrm{H}_{2}$ gas evolution rate for the $\mathrm{FTO} / \mathrm{V}_{2} \mathrm{O}_{5} / \mathrm{BiVO}_{4}$ and $\mathrm{FTO} / \mathrm{V}_{2} \mathrm{O} 5 / \mathrm{rGO} / \mathrm{BiVO}_{4}$ photoanodes are $8.17 \mu \mathrm{mol} / \mathrm{hr}$ and $32.7 \mu \mathrm{mol} / \mathrm{hr}$, respectively. This shows that both the $\mathrm{V}_{2} \mathrm{O}_{5}$ (i.e. forming heterojunction with $\mathrm{BiVO}_{4}$ ) and $\mathrm{rGO}$ (i.e. interlayer in $\mathrm{V}_{2} \mathrm{O}_{5} / \mathrm{BiVO}_{4}$ heterojunction) play an important role in promoting the effective separation of photogenerated charge carriers through prolonging the lifetime of the photogenerated electrons. With the dualelectrocatalyst configuration, the $\mathrm{H}_{2}$ gas evolution rate of the $\mathrm{FTO} / \mathrm{V}_{2} \mathrm{O}_{5} / \mathrm{rGO} / \mathrm{BiVO}_{4} / \mathrm{FeOOH} / \mathrm{NiOOH}$ photoanode was further increased to $44.96 \mu \mathrm{mol} / \mathrm{hr}$. This is more superior to that of the $\mathrm{FTO} / \mathrm{V}_{2} \mathrm{O}_{5} / \mathrm{BiVO}_{4}$ and $\mathrm{FTO} / \mathrm{V}_{2} \mathrm{O}_{5} / \mathrm{rGO} / \mathrm{BiVO}_{4}$ photoanodes by 5.5-fold and 1.4-fold, respectively. Based on these results, it is evidenced that the charge carriers separation, accumulation and recombination at the $\mathrm{FTO} / \mathrm{V}_{2} \mathrm{O}_{5} / \mathrm{rGO} / \mathrm{BiVO}_{4}$ heterojunction interfaces as well as the charge carriers injection efficiency are improved through the novel hierarchical photoanode structure with dual-electrocatalysts configuration. 

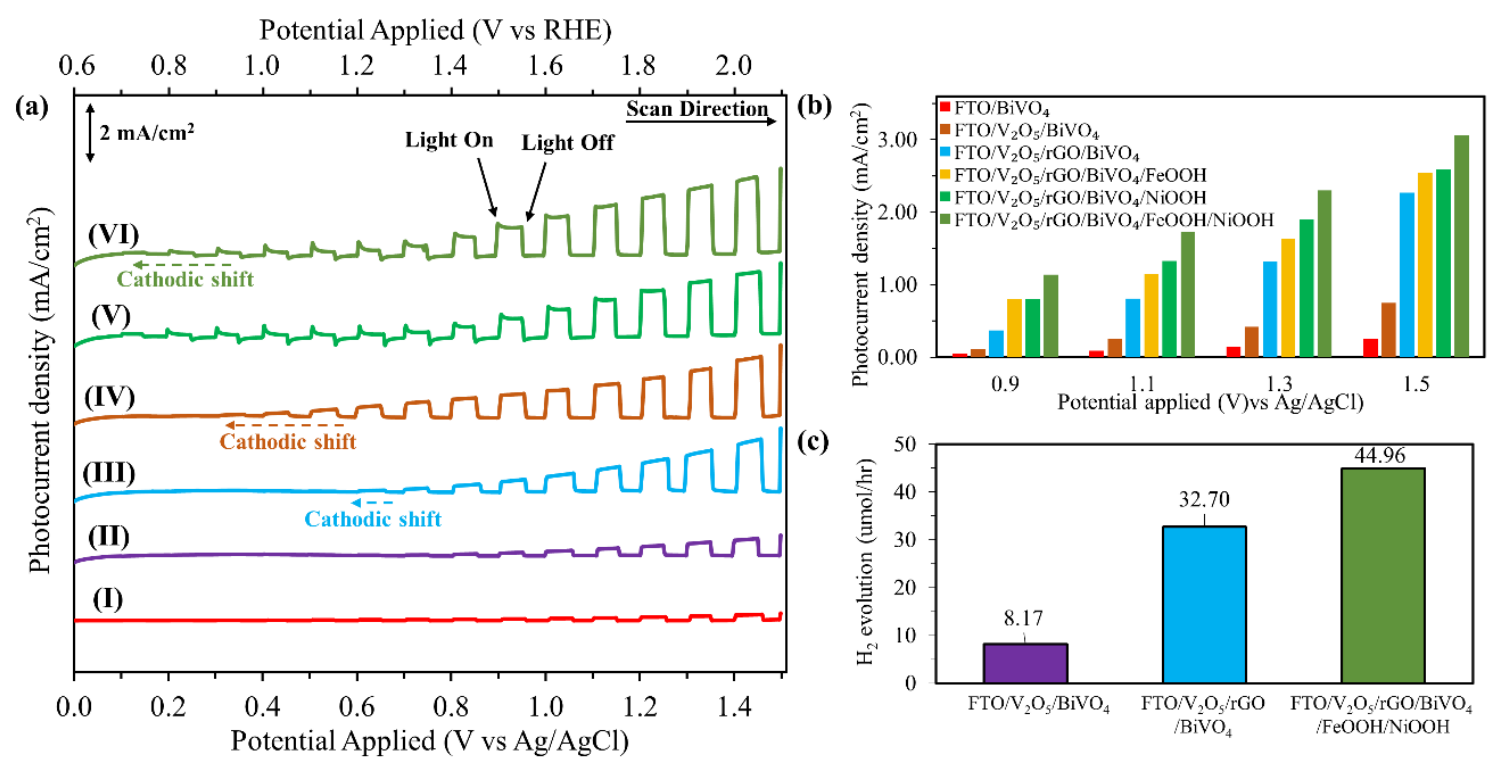

(c)

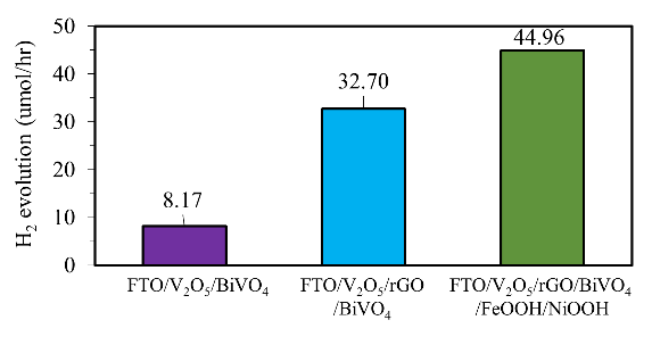

Fig. 3. (a) LSV measured with and without AM $1.5 \mathrm{G}$ illumination and (b) photocurrent density measured at different applied potentials for (i) $\mathrm{FTO} / \mathrm{BiVO}_{4}$, (ii) $\mathrm{FTO} / \mathrm{V}_{2} \mathrm{O}_{5} / \mathrm{BiVO}_{4}$, (iii) $\mathrm{FTO} / \mathrm{V}_{2} \mathrm{O}_{5} / \mathrm{rGO} / \mathrm{BiVO}_{4}$, $\mathrm{FTO} / \mathrm{V}_{2} \mathrm{O}_{5} / \mathrm{rGO} / \mathrm{BiVO}_{4} / \mathrm{FeOOH}$, $\mathrm{FTO} / \mathrm{V}_{2} \mathrm{O}_{5} / \mathrm{rGO} / \mathrm{BiVO}_{4} / \mathrm{NiOOH}$ and (vi) $\mathrm{FTO} / \mathrm{V}_{2} \mathrm{O}_{5} / \mathrm{rGO} / \mathrm{BiVO}_{4} / \mathrm{FeOOH} / \mathrm{NiOOH}$ photoanodes. (c) $\mathrm{H}_{2}$ gas evolution rate from $\mathrm{FTO} / \mathrm{V}_{2} \mathrm{O}_{5} / \mathrm{BiVO}_{4}$ and $\mathrm{FTO} / \mathrm{V}_{2} \mathrm{O}_{5} / \mathrm{rGO} / \mathrm{BiVO}_{4}$ and $\mathrm{FTO} / \mathrm{V}_{2} \mathrm{O}_{5} / \mathrm{rGO} / \mathrm{BiVO}_{4} / \mathrm{FeOOH} / \mathrm{NiOOH}$ photoanodes.

IMPS, a frequency-resolved optoelectric characterisation method, has been widely employed to obtain the function of applied potential in elucidating the dynamic of charge carriers transport processes [38]. This characterisation method is based on the sinusoidal modulation of illumination intensity in a wide range of frequencies with simultaneous measurement of the corresponding photocurrent responses. The lower semicircle (i.e. high frequency semicircle) provides information on the charge transport and relaxation in photoanode, whose intercept with $\mathrm{x}$-axis equals to the hole current without recombination. Whilst the upper semicircle (i.e. upper frequency semicircle), also known as recombination semicircle, corresponds to the competition between interfacial charge transfer and surface recombination. In this study, IMPS was used to investigate and gain a deeper understanding in the charge separation and collection dynamics for the photoanodes under AM $1.5 \mathrm{G}$ illumination. The role of $\mathrm{FeOOH}$ and $\mathrm{NiOOH}$ electrocatalyst thin films was investigated using IMPS, and the relevant IMPS responses of the FTO/BiVO $, \quad \quad F T O / V_{2} \mathrm{O}_{5} / \mathrm{BiVO}_{4}, \quad \mathrm{FTO} / \mathrm{V}_{2} \mathrm{O}_{5} / \mathrm{rGO} / \mathrm{BiVO}_{4} \quad$ and $\mathrm{FTO} / \mathrm{V}_{2} \mathrm{O}_{5} / \mathrm{rGO} / \mathrm{BiVO}_{4} / \mathrm{FeOOH} / \mathrm{NiOOH}$ photoanodes are presented in a complex plane in Fig. 
4 (a). From Fig. 4(a), it can be observed that only the pristine $\mathrm{BiVO}_{4}$ photoanode exhibits the recombination semicircle. The absence of recombination semicircle for other photoanodes indicates the charge carrier recombination is hindered, while the charge carrier transfer is more efficient with the construction of heterojunction structure and incorporation of rGO interlayer as electron mediator as well as the dual-electrocatalyst thin films. The average lifetime for photogenerated electrons to be diffused to the counter electrode through the external circuit can be estimated by using the following equation:

$\tau=\frac{1}{2 \pi f_{\min }}$

where $\tau$ is the transient time, and $f_{\min }$ is the frequency at which the minimum point in the IMPS plot occurs. By using Equation (3), the $\tau$ for photogenerated electrons in $\mathrm{FTO} / \mathrm{V}_{2} \mathrm{O}_{5} / \mathrm{rGO} / \mathrm{BiVO}_{4}, \mathrm{FTO} / \mathrm{V}_{2} \mathrm{O}_{5} / \mathrm{rGO} / \mathrm{BiVO}_{4} / \mathrm{FeOOH}, \mathrm{FTO} / \mathrm{V}_{2} \mathrm{O}_{5} / \mathrm{rGO} / \mathrm{BiVO}_{4} / \mathrm{NiOOH}$ and $\mathrm{FTOV}_{2} \mathrm{O}_{5} / \mathrm{rGO} / \mathrm{BiVO}_{4} / \mathrm{FeOOH} / \mathrm{NiOOH}$ photoanodes was estimated and as shown in Fig. 4 (b). From Fig. 4 (b), both the $\mathrm{FTO} / \mathrm{V}_{2} \mathrm{O}_{5} / \mathrm{rGO} / \mathrm{BiVO}_{4}$ and $\mathrm{FTO} / \mathrm{V}_{2} \mathrm{O}_{5} / \mathrm{rGO} / \mathrm{BiVO} / \mathrm{FeOOH}$ photoanodes show a relatively longer and same $\tau$ of $100.42 \mathrm{~ms}$ when compared to $\mathrm{FTO} / \mathrm{V}_{2} \mathrm{O}_{5} / \mathrm{rGO} / \mathrm{BiVO}_{4} / \mathrm{NiOOH}$ and $\mathrm{FTO} / \mathrm{V}_{2} \mathrm{O}_{5} / \mathrm{rGO} / \mathrm{BiVO}_{4} / \mathrm{FeOOH} / \mathrm{NiOOH}$ photoanodes with $\tau$ of $50.3 \mathrm{~ms}$ and $31.8 \mathrm{~ms}$, respectively. A shorter $\tau$ suggests the photogenerated electrons are effectively diffused to the counter electrode with a low fraction of photogenerated electrons being recombined. This finding is in concordant to the measured photocurrent density and $\mathrm{H}_{2}$ gas evolution rate shown in Fig. 3.

Fig. 4 (c) shows the photoluminescence (PL) spectra of $\mathrm{FTO} / \mathrm{BiVO}_{4}$, FTO/ $/ \mathrm{V}_{2} \mathrm{O}_{5} / \mathrm{rGO} / \mathrm{BiVO}_{4}$ and $\mathrm{FTO} / \mathrm{V}_{2} \mathrm{O}_{5} / \mathrm{rGO} / \mathrm{BiVO}_{4} / \mathrm{FeOOH} / \mathrm{NiOOH}$ photoanodes. Similarly, $\mathrm{PL}$ is an indicator tool to reveal the charge carrier trapping, migration and recombination processes in PEC photoanodes. The stronger PL spectrum intensity means that the photogenerated electrons and holes are prone to the recombination process, and the lifetime of the photogenerated electrons is short. In contrast, if the lifetime of the photogenerated electrons could be prolonged, the intensities of the luminous peaks in the corresponding PL spectrum will be very weak. From Fig. 4 (c), all the studied photoanodes exhibit similar PL spectra shapes with two luminous peaks at $483 \mathrm{~nm}$ and $534 \mathrm{~nm}$. The luminescence peak at $483 \mathrm{~nm}$ corresponds to the recombination of photogenerated hole formed in the $\mathrm{O}_{2 \mathrm{p}}$ band and the photogenerated electron in the $\mathrm{V}_{3 \mathrm{~d}}$ band, while the luminescence peak at $534 \mathrm{~nm}$ is due to the crystalline defects of $\mathrm{BiVO}_{4}$ [39]. Among all, the dual-electrocatalyst configuration photoanode of $\mathrm{FTO} / \mathrm{V}_{2} \mathrm{O}_{5} / \mathrm{rGO} / \mathrm{BiVO}_{4} / \mathrm{FeOOH} / \mathrm{NiOOH}$ achieved the lowest PL intensity 
which implied that the photogenerated electron-hole pairs possessed the highest transfer efficiency among the studied photoanodes.
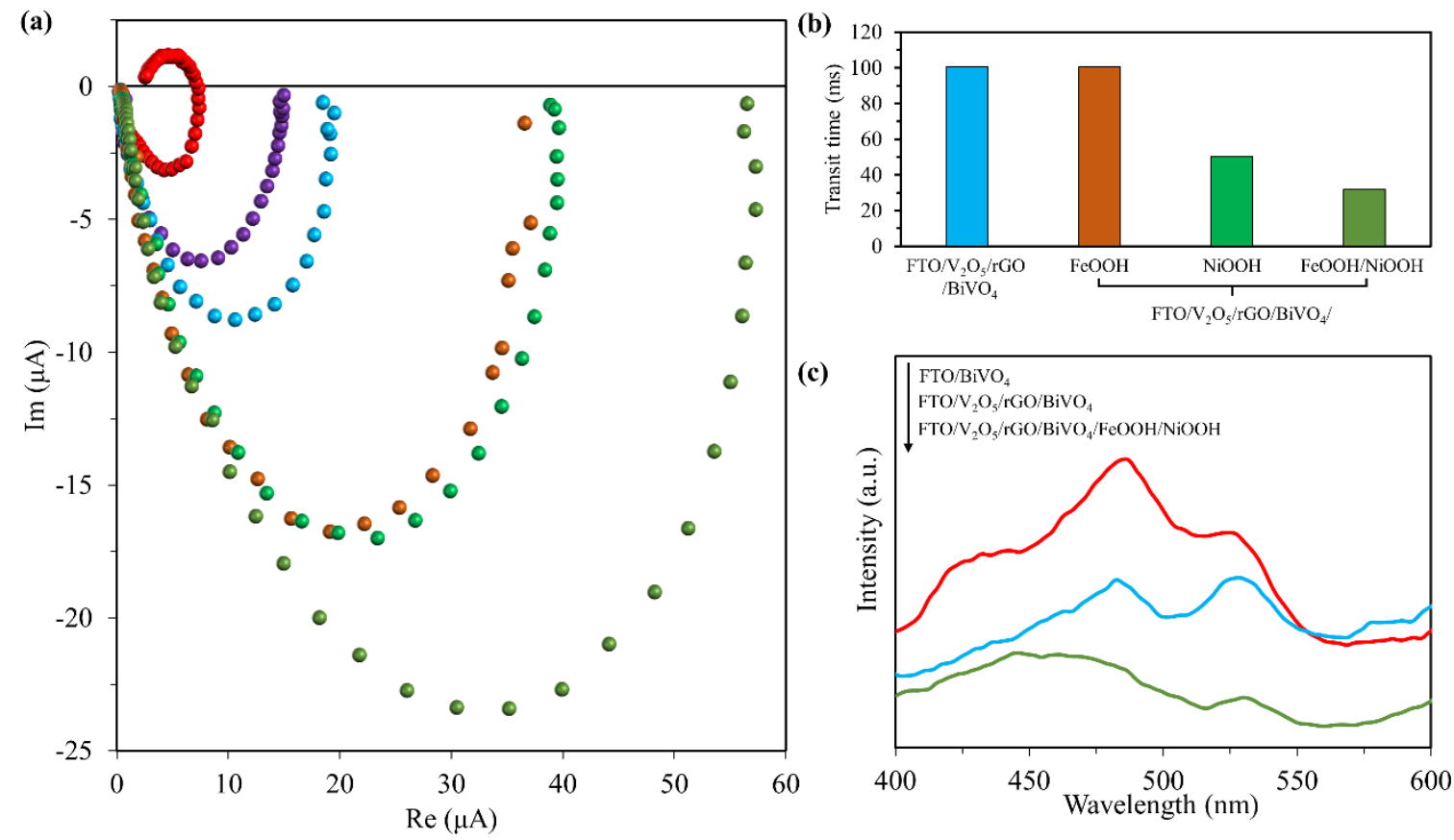

Fig. 4. (a) IMPS spectra measured at an applied potential of $1 \mathrm{~V}$ vs $\mathrm{Ag} / \mathrm{AgCl}$. (b) Transient time for photogenerated charges to reach the back contact of a photoanode. (c) PL spectra of the as-prepared photoanodes at room temperature. FTO/BiVO $4(\bigcirc), \mathrm{FTO} / \mathrm{V}_{2} \mathrm{O}_{5} / \mathrm{BiVO}_{4}(\mathrm{O})$, FTO/ $/ \mathrm{V}_{2} \mathrm{O}_{5} / \mathrm{rGO} / \mathrm{BiVO}_{4} \quad(0), \quad \mathrm{FTO} / \mathrm{V}_{2} \mathrm{O}_{5} / \mathrm{rGO} / \mathrm{BiVO}_{4} / \mathrm{FeOOH}$ $\mathrm{FTO} / \mathrm{V}_{2} \mathrm{O}_{5} / \mathrm{rGO} / \mathrm{BiVO}_{4} / \mathrm{NiOOH}(\mathrm{O})$ and $\mathrm{FTO} / \mathrm{V}_{2} \mathrm{O}_{5} / \mathrm{rGO} / \mathrm{BiVO}_{4} / \mathrm{FeOOH} / \mathrm{NiOOH}(O)$.

In order to further understand the kinetics of solar-driven PEC water splitting process in the presence of $\mathrm{FeOOH}$ and $\mathrm{NiOOH}$ electrocatalyst thin films on the $\mathrm{V}_{2} \mathrm{O}_{5} / \mathrm{rGO} / \mathrm{BiVO}_{4}$ photoanode, EIS analysis was performed using a three-electrode configuration with AM $1.5 \mathrm{G}$ illumination to investigate the potential reasoning on significantly enhanced photocurrent density and $\mathrm{H}_{2}$ gas evolution rate. Fig. 5 (a) shows the Nyquist plot consisting of experimental data (in dotted form) and fitted solid lines to the equivalent circuit (shown in the inset) by using the Metrohm Autolab NOVA software. EIS analysis in the form of Nyquist plot involves designing an equivalent circuit of capacitors and resistances that can represent the semiconductor-electrolyte interface, in order to gain a deeper insight into the interfacial charge transfer behavior in PEC cell. In Fig. 5 (a), the $\mathrm{x}$-axis represents the real part of measured impedance while the $y$-axis represents the negative number of the imaginary part of measured 
impedance. The Randles-Ershel fitting model was used in this study, where series resistance $\left(R_{s}\right)$ is the solution resistance, constant phase element $(Q)$ is capacitance associates with the Helmholtz layer at the electrode-solution interface, and charge-transfer resistance $\left(\mathrm{R}_{\mathrm{ct}}\right)$ is the charge transfer resistance across the interface of electrode/electrolyte.

Results showed that the mono-electrocatalyst configuration of $\mathrm{FTO} / \mathrm{V}_{2} \mathrm{O}_{5} / \mathrm{rGO} / \mathrm{BiVO}_{4} / \mathrm{FeOOH}$ and $\mathrm{FTO} / \mathrm{V}_{2} \mathrm{O}_{5} / \mathrm{rGO} / \mathrm{BiVO}_{4} / \mathrm{NiOOH}$ photoanodes were successful in reducing the $\mathrm{R}_{\mathrm{ct}}$ from $224.7 \Omega$ (i.e. for $\mathrm{FTO} / \mathrm{V}_{2} \mathrm{O}_{5} / \mathrm{rGO} / \mathrm{BiVO}_{4}$ ) to $140.8 \Omega$ and $107.8 \Omega$, respectively. A smaller $R_{\mathrm{ct}}$ value signifies an improved charge carrier transport across the electrode-electrolyte interface of the mono-electrocatalyst configuration photoanodes and thus, dramatically suppresses the electron-hole recombination and making favourable environment for PEC water splitting reactions. Additionally, the dual-electrocatalyst configuration photoanode of $\mathrm{FTO} / \mathrm{V}_{2} \mathrm{O}_{5} / \mathrm{rGO} / \mathrm{BiVO}_{4} / \mathrm{FeOOH} / \mathrm{NiOOH}$ was also analysed and fitted using the EIS Randles-Ershel model and it was found that the $\mathrm{R}_{\mathrm{ct}}$ value was further reduced to $97.1 \Omega$ when compared to the mono-electrocatalyst counterparts. This indicates that the presence of $\mathrm{FeOOH}$ and $\mathrm{NiOOH}$ could present a synergistic effect that further reduces the charge carrier transfer resistance and enhances the charge carrier transfer across the interface of electrode/electrolyte.

To further validate the EIS analysis, the charge injection efficiency of the studied photoanodes was evaluated by using aqueous $\mathrm{H}_{2} \mathrm{O}_{2}$ solution as the scavenger of photogenerated hole. Ideally, the rates of carrier charge transfer to the electrode/electrolyte interface is both thermodynamically and kinetically more facile in the presence of hole scavenger by assuming that the surface recombination of charge carrier is eliminated. In this instance, the difference in the measured photocurrent density with and without $\mathrm{H}_{2} \mathrm{O}_{2}$ is a direct testament of the charge carrier separation efficiency. From Fig. 5 (b), the measured photocurrent density curve for FTO/ $\mathrm{V}_{2} \mathrm{O}_{5} / \mathrm{BiVO}_{4}$ photoanode with the presence of $\mathrm{H}_{2} \mathrm{O}_{2}$ shows a very low photocurrent onset potential and a rapid increase in photocurrent density of up to $4.01 \mathrm{~mA} / \mathrm{cm}^{2}$ at $1.5 \mathrm{~V}$ vs $\mathrm{Ag} / \mathrm{AgCl}$. The difference in the measured photocurrent density was reduced with the introduction of $\mathrm{rGO}$ interlayer in the $\mathrm{FTO} / \mathrm{V}_{2} \mathrm{O}_{5} / \mathrm{rGO} / \mathrm{BiVO}_{4}$ photoanode, and this was further reduced with the incorporation of dual-electrocatalyst thin films of $\mathrm{FeOOH}$ and $\mathrm{NiOOH}$. This finding implies that the charge carrier recombination is significantly suppressed, and charge carrier separation efficiency is improved by promoting an efficient interfacial photogenerated electron transfer between $\mathrm{V}_{2} \mathrm{O}_{5}$ and $\mathrm{BiVO}_{4}$ and storing the photogenerated holes at the $\mathrm{NiOOH} /$ electrolyte interface that is necessary to allow OER to take place. 

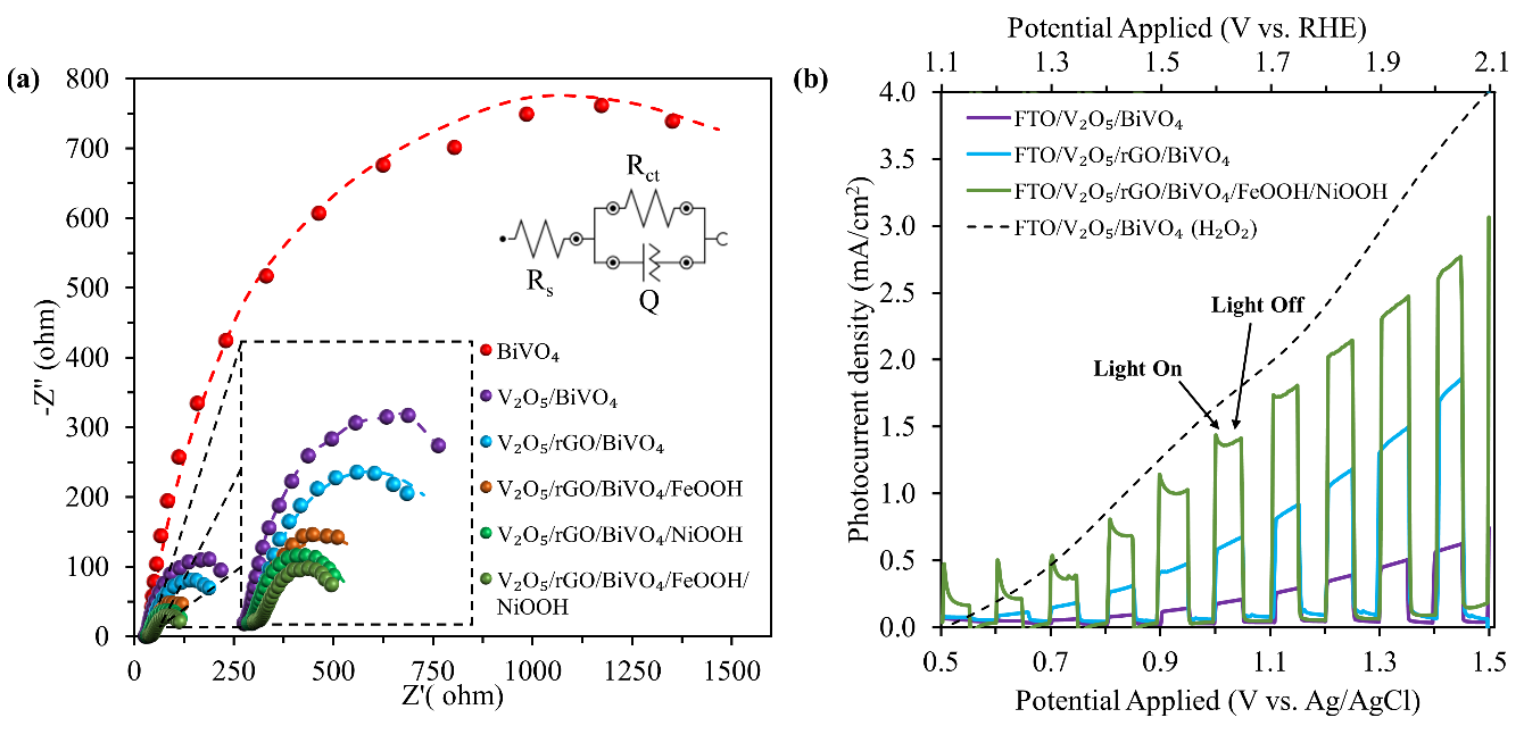

Fig. 5. (a) Nyquist plots of EIS of the studied photoanodes under AM 1.5 G illumination with equivalent circuit (inset). (b) $\mathrm{LSV}$ of the $\mathrm{FTO} / \mathrm{V}_{2} \mathrm{O}_{5} / \mathrm{BiVO}_{4}, \mathrm{FTO} / \mathrm{V}_{2} \mathrm{O}_{5} / \mathrm{rGO} / \mathrm{BiVO}_{4}$ and $\mathrm{FTO} / \mathrm{V}_{2} \mathrm{O}_{5} / \mathrm{rGO} / \mathrm{BiVO}_{4} / \mathrm{FeOOH} / \mathrm{NiOOH}$ photoanodes under $\mathrm{AM} 1.5 \mathrm{G}$ illumination with and without $\mathrm{H}_{2} \mathrm{O}_{2}$ as a hole scavenger.

Finally, the photostability of the novel hierarchical dual-electrocatalysts configuration photoanode is crucial for practical and sustained $\mathrm{H}_{2}$ gas evolution from the solar-driven PEC water splitting reaction. Fig. 6 shows the chronoamperometry curves recorded at different applied potential of $0.8 \mathrm{~V}, \quad 0.9 \mathrm{~V}$ and $1.0 \mathrm{~V}$ for $\mathrm{FTO} / \mathrm{V}_{2} \mathrm{O}_{5} / \mathrm{BiVO}_{4}$, $\mathrm{FTO} / \mathrm{V}_{2} \mathrm{O}_{5} / \mathrm{BiVO}_{4} / \mathrm{FeOOH} / \mathrm{NiOOH}$ and $\mathrm{FTO} / \mathrm{V}_{2} \mathrm{O}_{5} / \mathrm{rGO} / \mathrm{BiVO}_{4} / \mathrm{FeOOH} / \mathrm{NiOOH}$ photoanodes with duration of up to 1,800 s. From Fig. 6, it is evidenced that the photostability of $\mathrm{FTO} / \mathrm{V}_{2} \mathrm{O}_{5} / \mathrm{BiVO}_{4}$ photoanode is comparatively low with its photocurrent densities are decaying in the range of 66.6-73.9\% for the applied potential range of 0.8-1.0 V. Recently, Lee D.K. and Choi K.S. have reported that the dissolution of $\mathrm{V}^{5+}$ and the accumulation of photogenerated holes could initiate the photocorrosion of $\mathrm{BiVO}_{4}$ [40]. It was, however, with the presence of $\mathrm{FeOOH}$ and $\mathrm{NiOOH}$ electrocatalyst thin films on $\mathrm{FTO} / \mathrm{V}_{2} \mathrm{O}_{5} / \mathrm{BiVO}_{4}$ photoanode, the photocurrent decay rate was reduced owing the additional functionality of $\mathrm{FeOOH} / \mathrm{NiOOH}$ layer as a protection layer in preventing the $\mathrm{BiVO}_{4}$ from direct contact with electrolyte. Thus, the photocorrosion of $\mathrm{BiVO}_{4}$ can be prevented even if both the photogenerated electrons and holes are available at the surface of $\mathrm{BiVO}_{4}$. Results showed that the dual-electrocatalysts configuration photoanode was effective even at lower potentials. When a high potential is applied on the dual-electrocatalysts configuration photoanode, some 
photogenerated holes are accumulated in the $\mathrm{NiOOH}$ thin film that can be scavenged into the oxidation cycle of $\mathrm{Ni}(\mathrm{OH})_{2} / \mathrm{NiOOH}$ and further destabilise the photoanode [19]. Additionally, it was found that the presence of $\mathrm{rGO}$ interlayer in between $\mathrm{V}_{2} \mathrm{O}_{5}$ and $\mathrm{BiVO}_{4}$ in the $\mathrm{FTO} / \mathrm{V}_{2} \mathrm{O}_{5} / \mathrm{rGO} / \mathrm{BiVO}_{4} / \mathrm{FeOOH} / \mathrm{NiOOH}$ photoanode can further enhance the photostability of the photoanode.

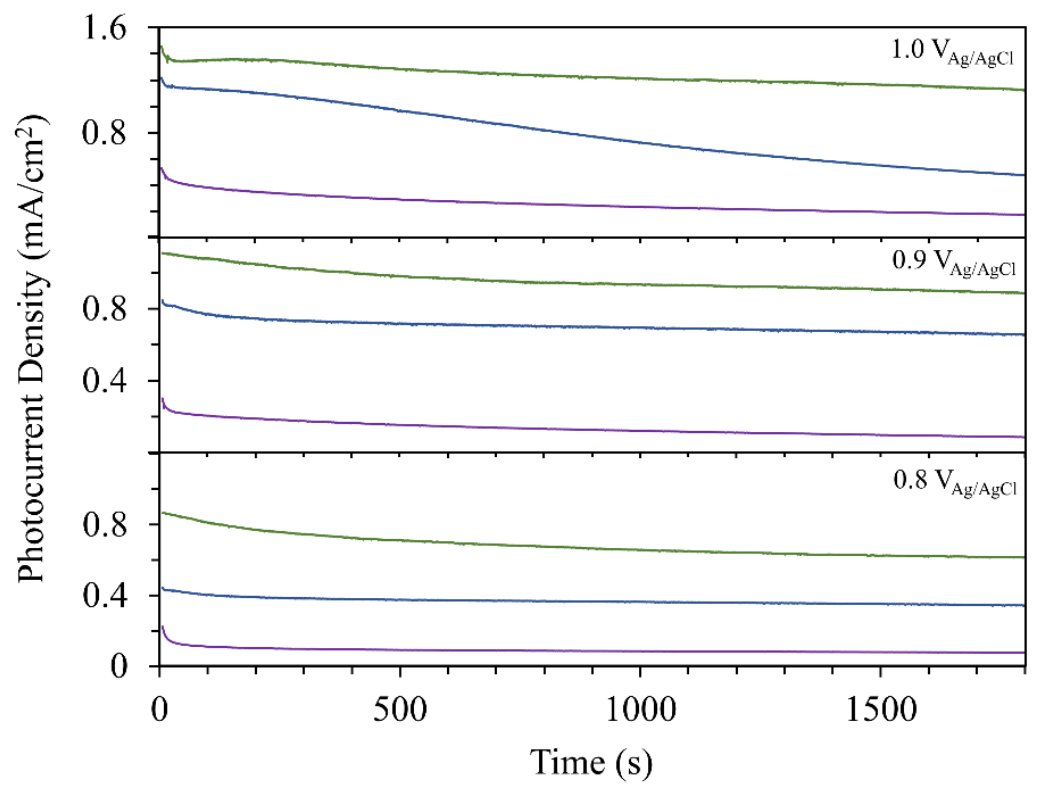

Fig. 6. Comparison of recorded chronoamperometry at different applied potential for $\mathrm{FTO} / \mathrm{V}_{2} \mathrm{O}_{5} / \mathrm{BiVO}_{4} \quad$ (Green), $\quad \mathrm{FTO} / \mathrm{V}_{2} \mathrm{O}_{5} / \mathrm{BiVO}_{4} / \mathrm{FeOOH} / \mathrm{NiOOH} \quad$ (Blue) and $\mathrm{FTO} / \mathrm{V}_{2} \mathrm{O}_{5} / \mathrm{rGO} / \mathrm{BiVO}_{4} / \mathrm{FeOOH} / \mathrm{NiOOH}$ (Purple) photoanodes.

Based on the overall results and discussion, three possible charge carrier transfer mechanisms in $\mathrm{FTO} / \mathrm{V}_{2} \mathrm{O}_{5} / \mathrm{rGO} / \mathrm{BiVO}_{4}$ photoanodes without electrocatalyst, with mono- and dualelectrocatalyst are proposed and elucidated in Fig. 7. Upon light irradiation of the $\mathrm{FTO} / \mathrm{V}_{2} \mathrm{O}_{5} / \mathrm{rGO} / \mathrm{BiVO}_{4}$ photoanode, photogenerated charge carriers will only be generated simultaneously in the $\mathrm{CB}$ of $\mathrm{BiVO}_{4}$ and $\mathrm{V}_{2} \mathrm{O}_{5}$. The photogenerated charge carriers will be transferred between $\mathrm{BiVO}_{4}$ and $\mathrm{V}_{2} \mathrm{O}_{5}$ through the conventional heterojunction mechanism. Whilst the photoinduced electrons in $\mathrm{CB}$ of $\mathrm{BiVO}_{4}$ will be injected into the $\mathrm{CB}$ of $\mathrm{fV}_{2} \mathrm{O}_{5}$, and the photogenerated holes in $\mathrm{VB}$ of $\mathrm{V}_{2} \mathrm{O}_{5}$ will be extracted and transferred to the $\mathrm{VB}$ of $\mathrm{BiVO}_{4}$. Therefore, the rate of interfacial charge carrier transfer between $\mathrm{BiVO}_{4}$ and $\mathrm{V}_{2} \mathrm{O}_{5}$ is a crucial aspect for mitigating the recombination of electron-hole pairs. With the formation of $\mathrm{C}$-Bi bond between $\mathrm{BiVO}_{4}$ and $\mathrm{rGO}$ interlayer, the lifetime of the photoinduced electrons from $\mathrm{CB}$ of 
$\mathrm{BiVO}_{4}$ is prolonged as well as enhancing the electronic transmission performance across the $\mathrm{FTO} / \mathrm{BiVO}_{4} / \mathrm{V}_{2} \mathrm{O}_{5}$ heterojunction structure. However, the photocurrent generation of $\mathrm{FTO} / \mathrm{V}_{2} \mathrm{O}_{5} / \mathrm{rGO} / \mathrm{BiVO}_{4}$ photoanode is still lower than that of the photocurrent generated with the presence of hole scavenger (i.e. $\mathrm{H}_{2} \mathrm{O}_{2}$ ). This is due to the accumulation of photogenerated holes at the interface states formed at the $\mathrm{BiVO}_{4} /$ electrolyte junction, which serves as the recombination center in promoting surface recombination of electron-hole pairs. Through this study, it can be seen that the issue with the accumulation of photogenerated holes can be inhibited through the introduction of $\mathrm{FeOOH}$ electrocatalyst on the $\mathrm{FTO} / \mathrm{V}_{2} \mathrm{O}_{5} / \mathrm{rGO} / \mathrm{BiVO}_{4}$ photoanode. The role of $\mathrm{FeOOH}$ electrocatalyst is to enhance the photogenerated holes transfer by harvesting them at the $\mathrm{VB}$ of $\mathrm{BiVO}_{4}$ and proceed by the water oxidation reaction. When the rate of interfacial photogenerated holes transfer for water oxidation is slower than the rate of photogenerated holes inflowing into the $\mathrm{FeOOH}$ electrocatalyst thin film, however, this will also lead to the partial accumulation of photogenerated holes at the $\mathrm{FeOOH}$ and $\mathrm{BiVO}_{4} / \mathrm{FeOOH}$ junction and causing surface recombination at $\mathrm{BiVO}_{4}$. From this study, it can be seen that the slow water oxidation kinetics can be overcome by introducing an additional layer of $\mathrm{NiOOH}$ electrocatalyst thin film on $\mathrm{FeOOH}$ to serves as the main water oxidation layer. During the water oxidation, the oxidation state of $\mathrm{NiOOH}$ will change from $\mathrm{Ni}^{3+}$ to a higher state of $\mathrm{Ni}^{4+}$ by extracting the accumulated photogenerated holes from $\mathrm{FeOOH}$. Subsequently, the $\mathrm{Ni}^{4+}$ state is reduced to $\mathrm{Ni}^{2+}$ by obtaining electrons from $\mathrm{H}_{2} \mathrm{O}$ to produce $\mathrm{O}_{2}$. Therefore, it can be clearly confirmed that the proposed strategy of utilising a dual-electrocatalyst configuration is able to suppress high surface charge carrier recombination limitation of $\mathrm{BiVO}_{4}$ through a two-step extraction of photogenerated holes from $\mathrm{BiVO}_{4}$ to $\mathrm{FeOOH}$ to $\mathrm{NiOOH}$. 

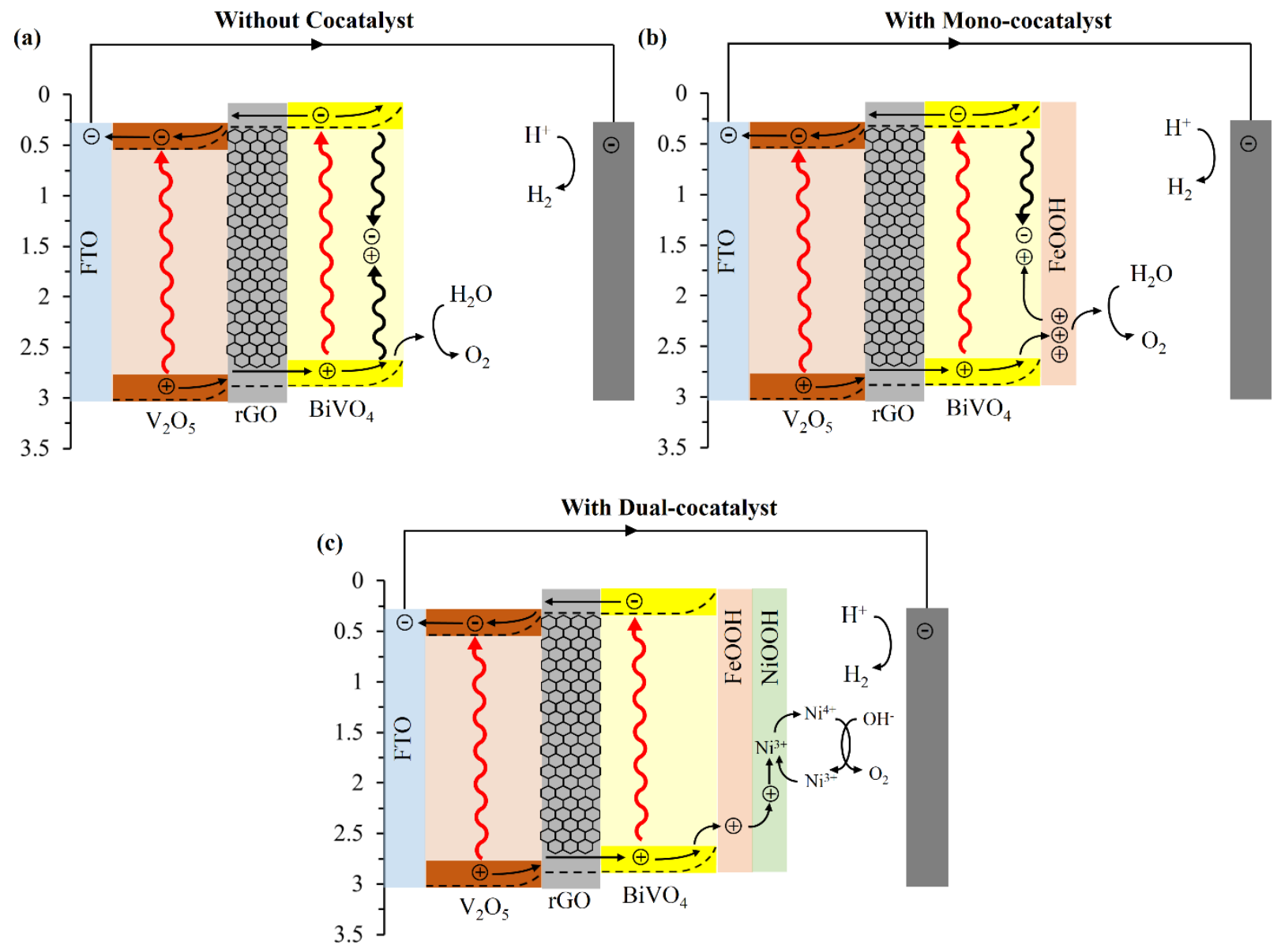

Fig. 7. Schematic of proposed interface charge carrier transfer mechanism for $\mathrm{FTO} / \mathrm{V}_{2} \mathrm{O}_{5} / \mathrm{rGO} / \mathrm{BiVO}_{4}$ photoanode (a) without electrocatalyst, (b) with mono-electrocatalyst and (c) with dual-electrocatalyst of under AM 1.5 G illumination for solar-driven PEC water splitting.

\section{Conclusion}

In this study, we have demonstrated the functionality of rGO interlayer and dual-electrocatalyst thin films as effective photogenerated electron collector and photogenerated hole extractor to suppress surface charge recombination in a novel hierarchical heterojunction photoanode structure, respectively. The dual-electrocatalyst configuration photoanode of FTO/ $\mathrm{V}_{2} \mathrm{O}_{5} / \mathrm{rGO} / \mathrm{BiVO}_{4} / \mathrm{FeOOH} / \mathrm{NiOOH}$ exhibited a significantly enhanced PEC performance due to its ability to suppress high surface charge carrier recombination limitation of the hierarchical heterojunction photoanode through a two-step extraction of photogenerated holes from $\mathrm{BiVO}_{4}$ to $\mathrm{FeOOH}$ to $\mathrm{NiOOH}$. The LSV analysis clearly indicated that the $\mathrm{FTO} / \mathrm{V}_{2} \mathrm{O}_{5} / \mathrm{rGO} / \mathrm{BiVO}_{4} / \mathrm{FeOOH} / \mathrm{NiOOH}$ photoanode achieved a remarkable photocurrent 
density of $3.06 \mathrm{~mA} / \mathrm{cm}^{2}$ at $1.5 \mathrm{~V}$ vs $\mathrm{Ag} / \mathrm{AgCl}$, which is 12-fold and 1.5-fold higher than that of FTO/BiVO 4 and $\mathrm{FTO} / \mathrm{V}_{2} \mathrm{O}_{5} / \mathrm{rGO} / \mathrm{BiVO}_{4}$ photoanodes as well as lowering and cathodically shifting the onset potential by $0.5 \mathrm{~V}$ to a final onset potential of $0.2 \mathrm{~V}$. Through the EIS and IMPS analysis, it was proven that the incorporation of photogenerated electron collector and photogenerated hole extractors are favourable in terms of fast charge carrier transfer process across the electrode/electrolyte interface, and a shorter transit time for the photogenerated electrons to be diffused to the counter electrode. Furthermore, it was found that the presence of dual-electrocatalyst thin films of $\mathrm{FeOOH}$ and $\mathrm{NiOOH}$ could serve as efficient protective layers to seclude the $\mathrm{BiVO}_{4}$ layer from electrolyte and preventing the anodic photocorrosion of $\mathrm{BiVO}_{4}$ from occurring. The enhancement in $\mathrm{H}_{2}$ gas evolution rate for the dual-electrocatalyst configuration photoanode indicating that most of the photogenerated charge carriers were consumed for the solar-driven PEC water splitting. Finally, three possible charge carrier transfer mechanisms in $\mathrm{FTO} / \mathrm{V}_{2} \mathrm{O}_{5} / \mathrm{rGO} / \mathrm{BiVO}_{4}$ photoanodes without electrocatalyst, with mono- and dual-electrocatalyst were proposed and elucidated to gain an in-depth understanding on the respective roles of $\mathrm{rGO}$ interlayer, $\mathrm{FeOOH}$ and $\mathrm{NiOOH}$ electrocatalyst thin films and their synergistic effects on enhancing the overall solar-driven PEC water splitting.

\section{Acknowledgement}

Prof. MN Chong is highly indebted to the Royal Society-Newton Advanced Fellowship (Reference No.: NA150418) awarded to him in collaboration with Prof. J Tang at the University College London (UCL) Solar Energy \& Advanced Materials group. Karam Puri and Yansen Dave Purwanto helped in the experimentation and data collection.

\section{Reference}

[1] A. Fujishima and K. Honda, Photoelectrolysis of water using titanium oxide, Nature 238 (1972) 37-38.

[2] T. Zhu, M.N. Chong, E.S. Chan, J.D. Ocon, Synthesis and characterisation of a novel bilayer tungsten trioxide nanojunction with different crystal growth orientation for improved photoactivity under visible light irradiation, J. Alloys Compd. 749 (2018) 268275. 
[3] Y. Bai, H. Bai, K. Qu, F. Wang, P. Guan, D. Xu, W. Fan, W. Shi, In-situ approach to fabricate $\mathrm{BiOI}$ photocathode with oxygen vacancies: Understanding the $\mathrm{N}_{2}$ reduced behavior in photoelectrochemical system, Chem. Eng. J. 362 (2019) 349-356.

[4] Y.W. Phuan, M.N. Chong, T. Zhu, S-T. Yong, E.S. Chan, Effects of annealing temperature on the physicochemical, optical and photoelectrochemical properties of nanostructured hematite thin films prepared via electrodeposition method, Mater. Res. Bull. 69 (2015) 71-77.

[5] Y.W. Phuan, W-J. Ong, M.N. Chong, J.D. Ocon, Prospects of electrochemically synthesized hematite photoanodes for photoelectrochemical water splitting: A review, J. Photochem. Photobiol. C 33 (2017) 54-82.

[6] T. Zhu, M.N. Chong, E.S. Chan, J.D. Ocon, J.D. Electrochemically-synthesized tungstate nanocomposites $\gamma-\mathrm{WO}_{3} / \mathrm{CuWO}_{4}$ and $\gamma-\mathrm{WO}_{3} / \mathrm{NiWO}_{4}$ thin films with improved band gap and photoactivity for solar-driven photoelectrochemical water oxidation, J. Alloys Compd. 762 (2018) 90-97.

[7] R. Wang, L. Luo, X. Zhu, Y. Yan, B. Zhang, X. Xiang, J. He, Plasmon-enhanced layered double hydroxide composite $\mathrm{BiVO}_{4}$ photoanodes: layering-dependent modulation of the water-oxidation reaction, ACS Appl. Energy Mater. 1 (2018) 3577-3586.

[8] M.N. Chong, S. Lei, B. Jin, C. Saint, C.W.K. Chow, Optimisation of an annular photoreactor process for degradation of Congo Red using a newly synthesized titania impregnated kaolinite nano-photocatalyst, Sep. Purif. Technol. 67 (2009) 355-363.

[9] P. Guan, H. Bai, F. Wang, H. Yu, D. Xu, W. Fan, W. Shi, In-situ anchoring Ag through organic polymer for configuring efficient plasmonic $\mathrm{BiVO}_{4}$ photoanode, Chem. Eng. J. 358 (2019) 658-665.

[10] A. Kudo, K. Omori, H. Kato, A novel aqueous process for preparation of crystal formcontrolled and highly crystalline $\mathrm{BiVO}_{4}$ powder from layered vanadates at room temperature and its photocatalytic and photophysical properties, J. Am. Chem. Soc. 121 (1999) 11459-11469.

[11] Y.W. Phuan, M.N. Chong, K. Egamparan, B-K. Lee, T. Zhu, E.S. Chan, Understanding the synergistic between optimum dopant loading and charge transfer kinetics in platinummediated nanostructured hematite thin films, J. Taiwan Inst. Chem. Eng. 66 (2016) 249257.

[12] X. Zhang, R. Wang, F. Li, Z. An, M. Pu, X. Xiang, Enhancing photoelectrochemical water oxidation efficiency of $\mathrm{BiVO}_{4}$ photoanodes by a hybrid structure of layered double hydroxide and graphene, Ind. Eng. Chem. Res. 56 (2017) 10711-10719. 
[13] C. Li, W. Fan, H. Lu, Y. Ge, H. Bai, W. Shi, Fabrication of Au@CdS/RGO/TiO 2 heterostructure for photoelectrochemical hydrogen production. New J. Chem. 40 (2016) 2287-2295.

[14] T. Hisatomi, J. Kubota, K. Domen, Recent advances in semiconductors for photocatalytic and photoelectrochemical water splitting. Chem. Soc. Rev. 43 (2014) 7520-7535.

[15] C. Zachäus, F.F. Abdi, L.M. Peter, R. van de Krol, Photocurrent of $\mathrm{BiVO}_{4}$ is limited by surface recombination, not surface catalysis. Chem. Sci. 8 (2017) 3712-3719.

[16] A. Shinde, D. Gueverra, G. Liu, I.D. Sharp, F.M. Toma, J.M. Gergoire, J.A. Haber, Discovery of $\mathrm{Fe}-\mathrm{Ce}$ Oxide/BiVO 4 Photoanodes through Combinatorial Exploration of Ni-Fe-Co-Ce Oxide Coatings, ACS Appl. Mater. Interfaces 8 (2016) 23696-23705.

[17] P. Guan, H. Bai, F. Wang, H. Yu, D. Xu, B. Chen, T. Xia, W. Fan, W. Shi, Boosting water splitting performance of $\mathrm{BiVO}_{4}$ photoanode through selective surface decoration of $\mathrm{Ag}_{2} \mathrm{~S}$, ChemCatChem 10 (2018) 4927-4933.

[18] T.W. Kim, K-S. Choi, Nanoporous $\mathrm{BiVO}_{4}$ photoanodes with dual-layer oxygen evolution catalysts for solar water splitting, Science 343 (2014) 990-994.

[19] L. Gao, J. Xie, X. Ma, M. Li, L. Yu, DNA@ $\mathrm{Mn}_{3}\left(\mathrm{PO}_{4}\right)_{2}$ Nanoparticles Supported with Graphene Oxide as Photoelectrodes for Photoeletrocatalysis. Nanoscale Res. Lett. 12 (2017) 17.

[20] B. Chen, Z. Zhang, M. Baek, S. Kim, W. Kim, K. Yong, An Antenna/Spacer/Reflector Based $\mathrm{Au} / \mathrm{BiVO}_{4} / \mathrm{WO}_{3} / \mathrm{Au}$ Nanopatterned Photoanode for Plasmon-Enhanced Photoelectrochemical Water Splitting. Appl. Catal. B Environ. 237 (2018) 763

[21] W. He, Y. Yang, L. Wang, J. Yang, X. Xiang, D. Yan, F. Li, Photoelectrochemical water oxidation efficiency of a core/shell array photoanode enhanced by a dual suppression strategy, ChemSusChem, 8 (2015) 1568-1576.

[22] W. He, R. Wang, L. Zhang, J. Zhu, X. Xiang, F. Li, Enhanced photoelectrochemical water oxidation on $\mathrm{BiVO}_{4}$ photoanode modified with multi-functional layered double hydroxide nanowalls, J. Mater. Chem. A 3 (2015) 17977-17982.

[23] D. Chen, Z. Liu, Z. Guo, W. Yan, Y. Xin, Enhancing light harvesting and charge separation of $\mathrm{Cu}_{2} \mathrm{O}$ photocathodes with spatially separated noble-metal cocatalysts towards highly efficient water splitting, J. Mater. Chem. A 6 (2018) 20393-20401.

[24] Z.H. Ibupoto, A. Tahira, P. Tang, X. Liu, J.R. Morante, M. Fahlman, J. Arbiol, M. Vagin, A. Vomiero, $\mathrm{MoS}_{\mathrm{x}} @ \mathrm{NiO}$ Composite Nanostructures: An Advanced Nonprecious Catalyst for Hydrogen Evolution Reaction in Alkaline Media. Adv. Funct. Mater. 29 (2018) 1807562. 
[25] N.P. Balsara, L.J. Fetters, N. Hadjichristidis, D.J. Lohse, C.C. Han, W.W. Graessley, R. Krishnamoorti, Thermodynamic interactions in model polyolefin blends obtained by small-angle neutron scattering. Macromolecules 25 (1992) 6137-6147.

[26] Z.Q. Liu, K. Qiu, H. Bai, F. Wang, Y. Ge, W. Cui, G. Zheng, J. Cui, W. Fan, Ni-MOF in-situ Decorating $\mathrm{ZnO}$ photoelectrode for photoelectrochemical water splitting, Funct. Mater. Lett. 11 (2018) 1850085.

[27] D. Li, J. Shi, C. Li, Transition-Meta-Based Electrocatalysts as Cocatalysts for Photoelectrochemical Water Splitting: A Mini Review. Small 14 (2018) 1704179.

[28] Y. Tang, R. Wang, Y. Yang, D. Yan, X. Xiang, Highly enhanced photoelectrochemical water oxidation efficiency based on triadic quantum dot/ layered double hydroxide/ $\mathrm{BiVO}_{4}$ photoanodes, ACS Appl. Mater. Interfaces 8 (2016) 19446-19455.

[29] C.S. Yaw, Q. Ruan, J. Tang, A.K. Soh, M.N. Chong, A Type II nn Staggered Orthorhombic $\mathrm{V}_{2} \mathrm{O}_{5} /$ Monoclinic Clinobisvanite $\mathrm{BiVO}_{4}$ Heterojunction Photoanode for Photoelectrochemical Water Oxidation: Fabrication, Characterisation and Experimental Validation, Chem. Eng. Sci. 364 (2019) 177-185.

[30] S. Wang, T. He, J-H. Yun, Y. Hu, M. Xiao, A. Du, L. Wang, New Iron-Cobalt Oxide Catalysts Promoting $\mathrm{BiVO}_{4}$ Films for Photoelectrochemical Water Splitting. Adv. Funct. Mater. 28 (2018) 1802685

[31] J.A. Seabold, K-S. Choi, Efficient and stable photo-oxidation of water by a bismuth vanadate photoanode coupled with an iron oxyhydroxide oxygen evolution catalyst. J. Am. Chem. Soc. 134 (2012) 2186-2192.

[32] S. Ho-Kimura, S.J.A. Moniz, A.D. Handoko, J. Tang, Enhanced photoelectrochemical water splitting by nanostructured $\mathrm{BiVO}_{4}-\mathrm{TiO}_{2}$ composite electrodes. J. Mater. Chem. A 2 (2014) 3948-3953.

[33] Y.W. Phuan, M.N. Chong, J.D. Ocon, E.S. Chan, A novel ternary nanostructured carbonaceous-metal-semiconductor eRGO/NiO/ $\alpha-\mathrm{Fe}_{2} \mathrm{O}_{3}$ heterojunction photoanode with enhanced charge transfer properties for photoelectrochemical water splitting. Sol. Energy Mater. Sol. Cells 169 (2017) 236-244.

[34] P. Xu, C. Miao, J. Feng, K. Cheng, K. Ye, J, Yin, D. Cao, G. Wang, Z. Cai, Q. Li, A novel material $\mathrm{NiOOH}$ directly grown on in-situ etched $\mathrm{Cu}(\mathrm{OH})_{2}$ nanowire with high performance of electrochemical energy storage. Electrochim. Acta 232 (2017) 445-455.

[35] J. Deng, Q. Zhang, K. Feng, H. Lan, J. Zong, M. Chaker, D. Ma, Efficient Photoelectrochemical Water Oxidation on Hematite with Fluorine-Doped FeOOH and FeNiOOH as Dual Cocatalysts. ChemSusChem 11 (2018) 3783. 
[36] Y.W. Phuan, E. Ibrahim, M.N. Chong, T. Zhu, B-K. Lee, J.D. Ocon, E.S. Chan, In situ Ni-doping during cathodic electrodeposition of hematite for excellent photoelectrochemical performance of nanostructured nickel oxide-hematite pn junction photoanode. Appl. Surf. Sci. 392 (2017) 144-152.

[37] Y.W. Phuan, M.N. Chong, T. Zhu, E.S. Chan, J.D. Ocon, Employing electrochemical reduced graphene oxide as a co-catalyst for synergistically improving the photoelectrochemical performance of nanostructured hematite thin films, J. Taiwan Inst. Chem. E. 71 (2017) 510-517.

[38] F. Giordano, A. Abate, J,P.C. Baena, M. Saliba, T. Matsui, S. H. Im, S. M. Zakeeruddin, M.K. Nazeeruddin, A. Hagfeldt, M. Graetzel, Enhanced electronic properties in mesoporous $\mathrm{TiO}_{2}$ via lithium doping for high-efficiency perovskite solar cells. Nature commun. 7 (2016) 10379.

[39] C, Karunakaran, S. Kalaivani, P. Vinayagamoorthy, S. Dash, Electrical, optical and visible light-photocatalytic properties of monoclinic $\mathrm{BiVO}_{4}$ nanoparticles synthesized hydrothermally at different pH. Mater. Sci. Semicond. Process 21 (2014) 122-131.

[40] D.K. Lee, K-S. Choi, Enhancing long-term photostability of $\mathrm{BiVO}_{4}$ photoanodes for solar water splitting by tuning electrolyte composition. Nat. Energy 3 (2018) 53. 